\title{
Detection of 6-monoacetylemorphine in hair sample of heroin addicts using gas chromatography-mass spectrometry and significance of rehabilitation program
}

\author{
Mohsin Ahmad Ghauri ${ }^{1 \dagger}$, Fahad Hassan ${ }^{1,2+}$, Younusa Hassan ${ }^{3}$, Naveel Atif ${ }^{1}$ and Ahmad Adnan ${ }^{2 *}$ (1)
}

\begin{abstract}
Background: The analysis of hair samples for the detection of drugs has become one of the convincing strategies in the field of forensic toxicology. A large number of cases concerning heroin abuse or its byproducts have been documented under the Control of Narcotic Substances Act, 1997, over the past decade. The present study was carried out with an aim to evaluate the primary metabolite of heroin, i.e., 6-monoacetylemorphine (6-MAM), in hair samples of addicts and subjects undergoing rehabilitation, thereafter accessing the success rate of the rehabilitation program at the de-addiction center.

Results: Hair samples were randomly collected from 20 regular heroin addicts and 20 heroin addicts from their past, from the rehabilitation center, of different age groups. Samples were cleaned, digested, and extracted using an alkaline digestion mediator methyl tertiary butyl ether, followed by quantification of 6-MAM via gas chromatographymass spectrometry (GC-MS). The mean concentration of 6-MAM in regular heroin addicts detected was $7.80 \mathrm{ng} / \mathrm{mg}$ and $2.34 \mathrm{ng} / \mathrm{mg}$ in samples of subjects undergoing rehabilitation at the de-addiction center, respectively.

Conclusion: Traces of 6-MAM in the hair sample of heroin addicts can be efficiently detected days after the last intake of heroin. In addition to that, our findings also give an idea for future evaluating the approximate timeframe for detection of 6-MAM and/or other metabolites of heroin in the hair sample. However, in the future, by carefully analyzing the hair samples that can be taken from rehabilitation centers from target subjects at different time intervals, the exact duration of traceable quantity of 6-MAM can be determined in the hair sample. Finally, it can be concluded that there is a significant success rate of the rehabilitation program at de-addiction centers in connection with dragging the 6-MAM level from the body.
\end{abstract}

Keywords: 6-Monoacetylemorphine, Heroin, GC-MS, Hair analysis, Rehabilitation

\section{Background}

Heroin is a semisynthetic opiate, its chemical name is diacetylmorphine (DAM), and it shares close structural features with morphine. Although it is used as a strong analgesic agent around the world, in the USA, it is no

\footnotetext{
* Correspondence: rock444_43@hotmail.com

${ }^{\dagger}$ Mohsin Ahmad Ghauri and Fahad Hassan contributed equally to this work. ${ }^{2}$ Department of Chemistry, Faculty of Life Science, Government College University, Lahore, Pakistan

Full list of author information is available at the end of the article
}

longer used clinically [1]. Similar to morphine and other poppy-derived agents, its relaxing and euphoric aptitude makes it a widespread drug of abuse. It is generally injected intravenously, even though it can be consumed by other means such as snorting, smoking, or inhaling its vapors. It shares the central structure of morphine, with the addition of 2 acetyl groups, which are believed to augment its permeation into the central nervous system [2]. It is generally metabolized by sequential removal of these acetyl groups; the loss of the first acetyl 
group converts heroin into 6-monoacetylmorphine (6MAM) [3]. The 6-MAM is a primary metabolite of heroin, and its presence is a definitive indication of heroin abuse. Like heroin, 6-MAM has a very short half-life; however, 6-MAM is further metabolized into morphine, the dominant metabolite of heroin. The detection of 6monoacetylmorphine establishes heroin exposure, but this metabolite has an extremely short half-life and is detectable in urine for only approximately $8 \mathrm{~h}$ after a single dose $[3,4]$. Heroin is a controlled substance; it interrupts the brain and causes euphoria (sense of well-being), hallucination (changes the perception), and how one feels and how one's body responds to pain sensation, making it a popular addictive drug. It is synthetically produced utilizing opium as its primary source. The manufacturing of heroin involves prior production of morphine, which is then chemically modified to obtain heroin [5]. Among various ways of detecting the presence of drugs and/or their metabolites such as 6-MAM and morphine in a human body, one method that is being broadly used in recent days for forensic analysis is hair sampling of the suspect [6,7]. Analysis of hair samples in the field of forensic science commenced in 1979 [8]. Baumgartner and colleagues thrived in spotting opiates in the hair samples of heroin addicts by using radioimmunoassay (RIA) and reckoning their corresponding opiate abuse histories by sectional analysis. As far as decomposition of hair is concerned, it is not much decomposable, rather it is an astonishing organic matrix that protects organic molecules [9]. It has the benefit, dependent upon its size, of permitting the expert to calculate the ingestion of a drug which might have taken place either a few days or several months before, and as an outcome, hair analysis is considered as a "timeline marker" for the former exposure to drugs [10]. The number of drugfacilitated crimes in Pakistan has increased significantly over the past two decades. According to the National Police Bureau NPB Publication Titled "Crime Data and Analysis (2001-2015)" Pakistan, a large number of drug abuse cases have been registered under the "Control of Narcotic Substances Act, 1997" over the last decade and those pertaining to the abuse of heroin or their derivatives contribute the highest percentage $[11,12]$. As has been witnessed by the authorities, in a number of cases, complaints against drug abusers were registered long after the quantity of drug ingested would have been eliminated naturally from the suspect's blood or urine $[13,14]$. The potential long-term historical record of drug exposure in hair could allow the detection of these otherwise short-lived analytes. Therefore, the present study was conducted with an aim to appraise the success rate of a de-addiction center by comparing the levels of 6-MAM traces in hair samples in regular heroin abusers and subjects (previously heroin addicts), undergoing rehabilitation at the de-addiction center, finally paving the way to develop a mechanism for estimating the retention time of 6-MAM in hair samples of addicts via gas chromatography-mass spectrometry (GC-MS) using an alkaline extracting agent methyl tertiary butyl ether (MTBE).

\section{Methods}

\section{Chemicals and reagents}

Dichloromethane (DCM), acetone, methyl tertiary butyl ether (MTBE), formic acid, and sodium hydroxide were all provided by the Department of Chemistry, Author University, Lahore, Pakistan, whereas Certified Reference Material (CRM) for internal standard deuterated 6MAM, of purity $\geq 99 \%$, was bought from Cayman Chemical (MI, USA).

\section{Sample collection}

After taking prior consent, 10-30 hair strands were taken from the scalps of each of the 20 random heroin addicts from a well-known area of Darbar Road at Lahore, Pakistan. A further 20 samples of subjects were taken, with prior consent, from Genius Rehab center situated at Barki Road, Lahore (Pakistan). The study approval was given by the Department of Chemistry and Life Sciences, Government College University, Lahore, with approval letter number, GCU/1-056/CLS. The participants were included after approval from the "Office of Research, Innovation and Commercialization" (ORIC) with reference number 2017-0057. All the participants were informed about the study protocol and then included after taking verbal consent. The inclusion criterion set for subjects at the rehabilitation center was those who have gone through at least 30 days of rehabilitation period against heroin abuse. The average duration of a patient at the rehabilitation center for sample collection, in our study, was 35 days. The hair samples from all participants were taken from the apex portion of the head, in order to avoid ambiguity in the dispersal of 6-MAM in hair due to inconstant rate of hair growth in different parts of the head (Tables 3 and 4).

\section{Sample inclusion criteria}

a) Only those individuals who had been admitted to the mentioned de-addiction center at least 30 days prior to the sample collection date were selected.

b) Healthy other than heroin addiction subjects of different age groups were included for this study.

\section{Sample exclusion criteria}

a) Individuals who got admitted to the mentioned deaddiction center against heroin abuse less than 30 days at the sample collection date were omitted from this study. 
b) Individuals who had not taken heroin for at least 3 days (for addicts) prior to the date of sample collection were not considered for this study.

c) Individuals presenting any psychotic disorder or any other physical complaint or comorbid situation were excluded from the study.

d) Individuals who had experienced any kind of surgery, cosmetic hair treatment, or bald were excluded from this study.

\section{Sample analysis}

Each round of hair analysis comprised of the following steps:

a) Sample decontamination

b) Digestion and extraction of the hair sample

c) Quantification of 6-MAM

\section{Sample decontamination}

Approximately, $50 \mathrm{mg}$ of each sample was washed at room temperature, firstly with distilled water for $5 \mathrm{~min}$, then with acetone for $1 \mathrm{~min}$, and finally with dichloromethane for $2 \mathrm{~min}$. The sample was air dried and then cut into small segments of about 3-4 mm [15].

\section{Digestion and extraction of the hair sample}

The washed samples were incubated with $500 \mu \mathrm{L}$ of $1 \mathrm{M}$ $\mathrm{NaOH}$ for $3 \mathrm{~h}$ in a water bath at $50{ }^{\circ} \mathrm{C}$ to allow for digestion. Samples were then extracted with $2 \mathrm{~mL}$ MTBE for 30-min rotary mixing and for 10-min centrifugation. Solvent layers were then shifted into clean tubes containing $150 \mu \mathrm{L} 1 \%$ formic acid, then mixed on a rotary mixer for $20 \mathrm{~min}$, and were removed after $10 \mathrm{~min}$ of centrifugation by aspiration. From the remaining aqueous layer, a $1-\mu \mathrm{L}$ sample was injected into the GC-MS system [16-18].

\section{Quantification of the 6-MAM}

Shimadzu's GC-MS-QP-2010 was used for the quantification of 6-MAM. The column was HP-5 crosslinked 5\% phenylmethyl polysiloxane fused-silica capillary column ( 25 $\mathrm{m}$ (length) $\times 0.32 \mathrm{~mm}$ (internal diameter) $\times 0.17 \mu \mathrm{m}$ (film thickness)). Helium of purity $99.9 \%$ was used as carrier gas. The temperature of the injector was $280{ }^{\circ} \mathrm{C}$ and the flow rate of the carrier gas was $1 \mathrm{~mL} / \mathrm{min}$. The temperature of the oven was maintained at $110{ }^{\circ} \mathrm{C}$ for $3 \mathrm{~min}$ at $10{ }^{\circ} \mathrm{C} / \mathrm{min}$, followed by $210{ }^{\circ} \mathrm{C}$ for $2 \mathrm{~min}$ at $10{ }^{\circ} \mathrm{C} / \mathrm{min}$, and finally at $300{ }^{\circ} \mathrm{C}$ for $5 \mathrm{~min}$ at $20{ }^{\circ} \mathrm{C} / \mathrm{min}$. SIM mode was used for quantitative analysis of 6-MAM $(m / z<300)$ [19].

\section{Method validation}

The method was validated in terms of selectivity, linearity, LOD, LLOQ, carry-over, precision and accuracy, recovery, and stability according to the protocols established previously $[20,21]$.
To evaluate selectivity, blank hair samples obtained from five different origins were analyzed to determine endogenous compounds or potential interferences released from the matrix. LOD and LLOQ were measured by evaluating the signal/noise $(\mathrm{S} / \mathrm{N})$ ratio of 10 replicates of blank hair for each compound at proper concentrations. LOD was calculated on the basis of the concentration with a $\mathrm{S} / \mathrm{N}>3$, while the concentrations of the target compounds with a $\mathrm{S} / \mathrm{N}>10$ were chosen as LLOQ. The absence of carry-over was evaluated by injecting at the highest point of the calibration curve, followed by a solvent blank, and measuring the peak area at the retention times of the target compounds under investigation. For routine analysis of hair samples, ethyl acetate blanks were run between each pair of samples. The linearity of the method was evaluated over the concentration ranges of $0.1-25 \mathrm{ng} / \mathrm{mg}$ for the sample in both groups and was expressed by the determination coefficient $\left(R^{2}\right)$. The calibration curves were obtained by least-squares linear regression. The intra-day precision and accuracy of the method were established by eight independent determinations of the samples $(n=8)$. The inter-day precision and accuracy were determined in two different days for the aforementioned replicates over a 5-day gap for each replicate. To determine the precision, the coefficients of variations $(\mathrm{CV} \%)$ were calculated for the replicate measurements. Accuracy (bias\%) was expressed as the relative error of the calculated concentrations and was calculated by the degree of agreement between the measured and the nominal concentrations of the QC samples. For recovery determination, QC samples were prepared at three concentration levels. The recovery was determined by comparing the absolute peak area $(A)$ of the compound for the QC samples prepared in three replicates with the absolute peak area $(B)$ of the target compound for the samples processed as blank and spiked at the same concentration level. The recovery was calculated using the following equation: Recovery $(\%)=A / B \times 100$. Sample stability was assessed by repeated analysis of low-concentration $\mathrm{QC}$ and highconcentration QC samples $(n=3)$, spiked at mentioned concentrations. To examine the stability, QC hair samples were left for 10 days prior to sample preparation and analysis. The internal standard used was a deuterated 6-MAM. These samples were analyzed, and the peak area ratios were compared with the ones obtained by the analysis of freshly prepared samples.

\section{Results}

Method validation

\section{Selectivity}

Five different hair samples obtained from non-heroin users were examined in a selectivity test. There were no interfering peaks at the retention times of the target 
Table 1 Calibration method for sample

\begin{tabular}{llllllll}
\hline Groups & Conc $\mathbf{n g} / \mathbf{m g}$ & $\boldsymbol{t}_{\mathrm{R}} \mathbf{m i n}$ & Slope $($ mean \pm S.D) & $\boldsymbol{y}$-intercept & Linearity $^{\mathbf{a}}\left(\boldsymbol{R}^{\mathbf{2}}\right)$ & LOD $^{\mathbf{b}}(\mathbf{n g} / \mathbf{m g})$ & $\mathbf{L L O Q}^{\mathbf{c}}(\mathbf{n g} / \mathbf{m g})$ \\
\hline Addicts' group & $0.1-25$ & 7.23 & $0.334 \pm 0.010$ & 0.0572 & 0.9984 & 0.0745 & 0.22 \\
Rehab group & $0.1-25$ & 7.22 & $0.265 \pm 0.032$ & 0.0412 & 0.9937 & 0.0311 & 0.09
\end{tabular}

${ }^{\mathrm{a}}$ Linearity is described by the determination coefficient for the calibration curve $(y=a x+b)$. ${ }^{\mathrm{b}}$ The limit of detection (LOD) was based on the concentration corresponding to a signal plus 3 standard deviations from the mean of 10 replicates of the blank hair. ${ }^{\mathrm{C}}$ The lower limit of quantification (LLOQ) was defined as the lowest concentration on the calibration curve with precision (CV\%) less than $20 \%$ and accuracy (bias\%) within $\pm 20 \%$

compound and IS. Representative chromatograms obtained from blank hair and spiked hair samples are shown in Fig. 3.

\section{Linearity}

The linearity was tested in the concentration ranges of $0.1-25.0 \mathrm{ng} / \mathrm{mg}$ for samples in both groups. The resultant values displayed calibration parameters like slope, intercept, and coefficient of determination found from the calibration curves $(n=3)$. The $R^{2}$ values for the linear regression were above 0.990 for under investigation compounds in both groups, indicating excellent fitting. The calculated limit of detection (LOD) values for the regular addict group and rehab groups were 0.0745 and $0.0311 \mathrm{ng} / \mathrm{mg}$, respectively, while the lower limit of quantification (LLOQ) values were 0.22 and $0.09 \mathrm{ng} / \mathrm{mg}$, respectively. The retention time of 6-MAM for the rehab group was $7.22 \mathrm{~min}$ whereas for the regular addicts' group it was $7.23 \mathrm{~min}$ (Table 1).

\section{Recovery, accuracy, and precision}

The recovery, accuracy, and precision are summarized in Table 2. The analytical recoveries were determined at three concentration levels in three replicates. The mean recoveries (\%) for the target compound ranged from 86.84 to $91.78 \%$ and from 87.81 to $93.62 \%$ for 6-MAM in addicts and rehab groups, respectively. The intra-day and inter-day precisions for addicts and rehab groups were 0.8 to $8.1 \%$ and 0.6 to $2.6 \%$ and 3.9 to $4.9 \%$ and 2.3 to $6.9 \%$, respectively, whereas the intra-day and inter-day accuracies for both groups were ranged from -5.1 to $4.7 \%$ and -8.7 to $-1.2 \%$ and -4.2 to $2.9 \%$ and -4.8 to $1.1 \%$, respectively.
These data were within the acceptance criteria of $15 \%$ of nominal concentration for low, middle, and highquality control $(\mathrm{QC})$ concentrations.

\section{Carry-over and stability}

To evaluate the absence of carry-over, the highest extracted calibrator was injected into the GC-MS instrument, followed by an ethyl acetate blank. Potential carry-over effects were not observed. For practical purposes, ethyl acetate blanks were used throughout the sample sequence to verify that no sample-to-sample contamination occurred. Stability experiments were performed to identify any possible variation due to storage time. Low- and high-concentration QC samples were analyzed using a method developed in this study. The results from the stability experiments indicate that the samples were stable under normal storage conditions. No significant loss of the target compound of 6-MAM was observed at room temperature for 10 days.

\section{Sample characteristics}

The random heroin addicts' group had a mean age of 29.70 (SD 8.6, 17-46 years) and had mainly black hair color (75\%) and mean duration of drug abuse of 3.3 years and median 6-MAM levels $7.815 \mathrm{ng} / \mathrm{mg}$ with SD 1.804, and the limit of detection was $0.1 \mathrm{ng} / \mathrm{mg}$ (Tables 3 and 4). The subjects from the rehab group had a mean age of 27.75 (SD 7.5, 17-46 years) and mean duration of heroin abuse of 4.8 years and median 6-MAM levels $2.3445 \mathrm{ng} / \mathrm{mg}$ with SD 1.548, and the limit of detection was $0.1 \mathrm{ng} / \mathrm{mg}$ [14] (Tables 5 and 6). The results suggest that the heroin addicts belonging to both groups had similar characteristics

Table 2 Results of accuracy, precision, and recovery for method validation using quality control (QC) samples

\begin{tabular}{|c|c|c|c|c|c|c|}
\hline \multirow[t]{2}{*}{ Groups } & \multirow[t]{2}{*}{ QC ng/mg } & \multirow[t]{2}{*}{ Recovery (\%) } & \multicolumn{2}{|l|}{ Intra-day $n=8$} & \multicolumn{2}{|l|}{ Inter-day $n=16$} \\
\hline & & & Precision $^{\mathrm{a}}$ (CV\%) & Accuracy $^{\mathbf{b}}$ (bias\%) & Precision (CV\%) & $\overline{\text { Accuracy (bias\%) }}$ \\
\hline \multirow[t]{3}{*}{ Addicts' group } & 1.5 & 86.84 & 8.1 & 4.7 & 4.9 & 2.9 \\
\hline & 3 & 91.18 & 1.5 & -1.2 & 4.6 & -1.4 \\
\hline & 6 & 91.78 & 0.8 & -5.1 & 3.9 & -4.2 \\
\hline \multirow[t]{3}{*}{ Rehab group } & 1.5 & 87.81 & 2.6 & -8.7 & 6.9 & 1.1 \\
\hline & 3 & 93.62 & 1.1 & -1.2 & 3.6 & -1.9 \\
\hline & 6 & 90.84 & 0.6 & -4.6 & 2.3 & -4.8 \\
\hline
\end{tabular}

${ }^{a}$ Expressed as the relative standard deviation of the peak area ratios of the target compound/IS. ${ }^{b}$ Calculated as [(calculated mean concentration - nominal concentration)/nominal concentration] $\times 100$ 
Table 3 6-MAM levels in regular addicts' group

\begin{tabular}{|c|c|c|c|c|}
\hline Sample no. & Code & Age & Duration (years) & Qty 6-MAM ng/mg \\
\hline 1 & LHR 1 & 36 & 6 & 9.61 \\
\hline 2 & LHR 2 & 17 & 1 & 6.73 \\
\hline 3 & LHR 3 & 23 & 2 & 5.46 \\
\hline 4 & LHR 4 & 29 & 4 & 8.32 \\
\hline 5 & LHR 5 & 22 & 1 & 5.94 \\
\hline 6 & LHR 6 & 29 & 3 & 7.65 \\
\hline 7 & LHR 7 & 35 & 2 & 5.85 \\
\hline 8 & LHR 8 & 38 & 3 & 6.31 \\
\hline 9 & LHR 9 & 19 & 2 & 7.98 \\
\hline 10 & LHR 10 & 42 & 3 & 5.79 \\
\hline 11 & LHR 11 & 39 & 5 & 9.63 \\
\hline 12 & LHR 12 & 44 & 4 & 8.78 \\
\hline 13 & LHR 13 & 31 & 6 & 9.95 \\
\hline 14 & LHR 14 & 30 & 2 & 5.69 \\
\hline 15 & LHR 15 & 19 & 1 & 6.67 \\
\hline 16 & LHR 16 & 17 & 1 & 6.11 \\
\hline 17 & LHR 17 & 24 & 3 & 10.74 \\
\hline 18 & LHR 18 & 26 & 5 & 9.63 \\
\hline 19 & LHR 19 & 33 & 7 & 10.63 \\
\hline 20 & LHR 20 & 41 & 5 & 8.56 \\
\hline Avg & & $=29.7$ & $=3.3$ & $=7.8015 \pm 1.804$ \\
\hline
\end{tabular}

Table 4 6-MAM level in subjects undergoing rehabilitation at the de-addiction center

\begin{tabular}{|c|c|c|c|c|c|}
\hline Sample no. & Code & Age & $\begin{array}{l}\text { Duration } \\
\text { (years) }\end{array}$ & $\begin{array}{l}\text { 6-MAM } \\
\mathrm{ng} / \mathrm{mg}\end{array}$ & $\begin{array}{l}\text { Days spent } \\
\text { in the rehab } \\
\text { center }\end{array}$ \\
\hline 1 & DAC 1 & 21 & 3 & 0.76 & 32 \\
\hline 2 & DAC 2 & 25 & 4 & 0.91 & 39 \\
\hline 3 & DAC 3 & 23 & 2 & 1.67 & 31 \\
\hline 4 & DAC 4 & 22 & 5 & 2.84 & 36 \\
\hline 5 & DAC 5 & 27 & 3 & 1.73 & 33 \\
\hline 6 & DAC 6 & 29 & 6 & 4.39 & 42 \\
\hline 7 & DAC 7 & 41 & 5 & 4.36 & 41 \\
\hline 8 & DAC 8 & 29 & 8 & 4.65 & 37 \\
\hline 9 & DAC 9 & 27 & 4 & 3.32 & 33 \\
\hline 10 & DAC 10 & 22 & 2 & 0.47 & 31 \\
\hline 11 & DAC 11 & 30 & 6 & 4.56 & 30 \\
\hline 12 & DAC 12 & 33 & 7 & 3.39 & 30 \\
\hline 13 & DAC 13 & 42 & 3 & 2.75 & 38 \\
\hline 14 & DAC 14 & 21 & 4 & 1.29 & 34 \\
\hline 15 & DAC 15 & 18 & 2 & 0.39 & 39 \\
\hline 16 & DAC 16 & 19 & 3 & 0.54 & 35 \\
\hline 17 & DAC 17 & 26 & 6 & 1.33 & 34 \\
\hline 18 & DAC 18 & 27 & 4 & 0.86 & 33 \\
\hline 19 & DAC 19 & 45 & 13 & 4.41 & 36 \\
\hline 20 & DAC 20 & 28 & 6 & 2.27 & 33 \\
\hline Avg & & $=27.75$ & $=4.8$ & $=2.3445 \pm 1.548$ & $=34.85$ \\
\hline
\end{tabular}

Table 5 Demographics of the regular addicts and subjects from de-addiction center groups

\begin{tabular}{lll}
\hline Variable & $\begin{array}{l}\text { Regular addicts' group } \\
\boldsymbol{n}(\%)\end{array}$ & $\begin{array}{l}\text { Addicts from the } \\
\text { de-addiction } \\
\text { center group } \\
\boldsymbol{n}(\%)\end{array}$ \\
\hline $\begin{array}{l}\text { Age group } \\
\text { 17-26 years }\end{array}$ & $8(40)$ & $9(45)$ \\
$27-36$ years & $7(35)$ & $8(40)$ \\
$37-46$ years & $5(25)$ & $3(15)$ \\
\hline
\end{tabular}

but there was a remarkable difference in mean 6MAM levels between the two groups with lower mean 6-MAM levels in addicts undergoing rehabilitation at the de-addiction center group. This establishes a realistic efficiency of the de-addiction center as compared to the random addicts' group.

\section{Hair sample and 6-MAM concentrations Interpretation of the mass spectrum for regular addicts' sample}

The key ions detected in this spectrum were of 6monoacetylmorphine and morphine forming peaks at $m / z 327$ and 286, respectively. The mass-spectral fragmentation of these two key ions detected in this spectrum included a fragment forming a peak at $\mathrm{m} / \mathrm{z}$ 229 , formed due to the loss of $\mathrm{CH}_{2} \mathrm{CHNCH}_{3}$ from the original morphine compound. The loss of $\mathrm{H}_{2} \mathrm{O}$ and $\mathrm{CH}_{3} \mathrm{CH}=\mathrm{O}$ from the fragment ion at $m / z 229$ results in the formation of fragment ions with peaks at $m / z 211$ and $m / z 185$, respectively. The loss of $\mathrm{CO}_{2}$ from the ion at $m / z 185$ results in the formation of fragment ion at $m / z$ 157. The presence of morphine as well as 6monoacetylmorphine along with the typical mass fragment pattern of morphine and other opiates (Fig. 1a, b) confirmed the abuse of heroin.

\section{Interpretation of the mass spectrum of the sample from the de-addiction center group}

The key ions detected in this spectrum were 6monoacetylemorphine and morphine forming peaks at $(m / z) 331$ and 286, respectively. The mass-spectral

Table 6 Statistics for regular addicts and subjects at deaddiction center groups

\begin{tabular}{lll}
\hline Variable & $\begin{array}{l}\text { Random addicts' } \\
\text { group }(\boldsymbol{n}=\mathbf{2 0})\end{array}$ & $\begin{array}{l}\text { Addicts from } \\
\text { the de-addiction } \\
\text { center group } \\
(\boldsymbol{n}=\mathbf{2 0})\end{array}$ \\
\hline Mean age (years) & 29.70 & 27.75 \\
Duration in years (mean) & 3.30 & 4.80 \\
6-MAM levels in ng/mg (mean) & 7.8015 & 2.3445 \\
6-MAM levels in ng/mg (median) & 7.815 & 2.000 \\
6-MAM levels in ng/mg (SD) & 1.804 & 1.548 \\
\hline
\end{tabular}




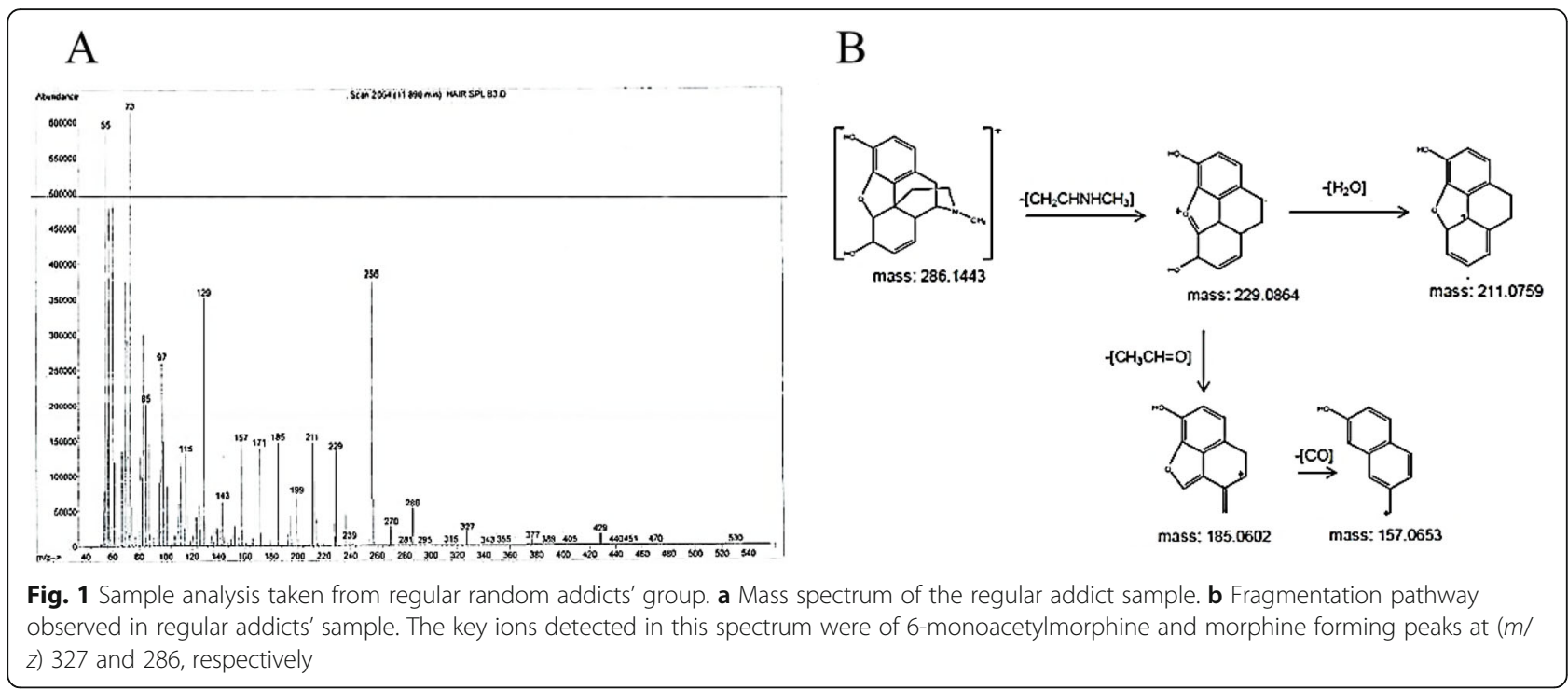

fragmentation of morphine key ion detected in this spectrum included a fragment forming a peak at $\mathrm{m} / \mathrm{z}$ 229, formed due to the loss of $\mathrm{CH}_{2} \mathrm{CHNCH}_{3}$ from the original morphine compound. The loss of $\mathrm{CH}_{3} \mathrm{CH}=\mathrm{O}$ from the fragment ion at $m / z 229$ results in the formation of fragment ion with peaks at $m / z 185$. The loss of $\mathrm{CO}_{2}$ from the ion at $\mathrm{m} / z 185$ results in the formation of fragment ion at $m / z$ 157. The presence of morphine along with the typical mass fragment pattern of morphine (Fig. 2a, b) confirmed the prior abuse of heroin.

\section{Normality test}

The data were first tested for normality by applying the Kolmogorov-Smirnov test and Shapiro-Wilk's test. The Kolmogorov-Smirnov statistic (0.100, d.f 40, P 0.200) and Shapiro-Wilk's statistic (0.943, d.f 40, P 0.042) combined signify that the data is not normally distributed. Furthermore, Levene's statistics were applied to test for the difference of normality between the two groups. The results of Levene's statistics $(0.878$, d.f $1,37.99, P$ 0.355) suggest that there is no significant difference in variance between the two groups. Leven's statistics further justifies the application of the Mann-Whitney $U$ test for comparison of the two groups since the data were not normally distributed. Table 7 shows the actual value of Mann-Whitney $U$ statistics along with the $P$-value. From this data, it can be concluded that the 6-MAM levels in the random heroin addicts' group are significantly higher as compared to subjects from the deaddiction center group $(U=0.000, P=0.000)$.

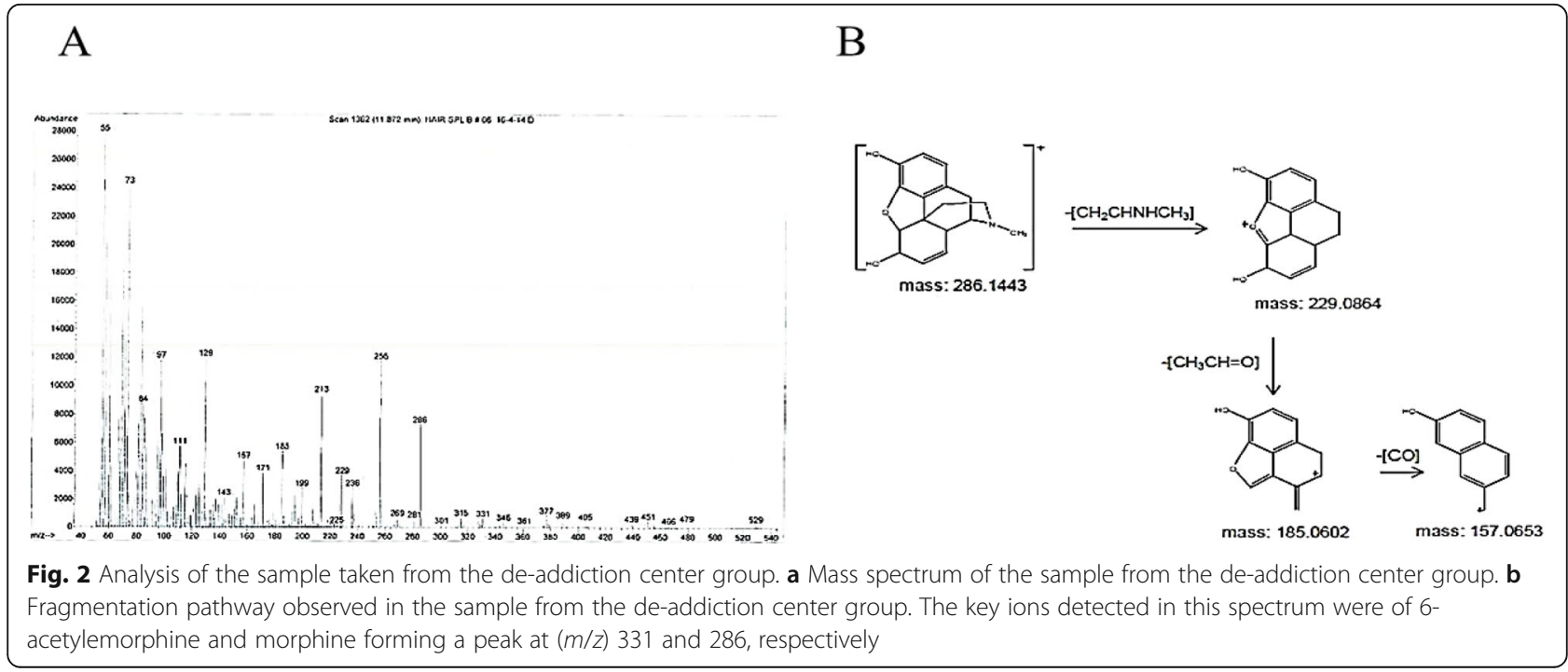


Table 7 Mann-Whitney $U$ test statistics

\begin{tabular}{ll}
\hline & 6-MAM (ng/mg) \\
\hline Mann-Whitney $U$ & .000 \\
Wilcoxon W & 210.000 \\
$Z$ statistics & -5.410 \\
Asymp. Sig. (2-tailed) & $.000^{*}$ \\
\hline *Te r
\end{tabular}

*The results are highly significant since the $P$-value is less than $<0.05$

Figure 3 shows the mean ranks of the groups under study and suggests that the random heroin addicts' group has a higher mean rank as compared to subjects undergoing rehabilitation at the de-addiction center. This implies that the random heroin addicts' group has higher 6-MAM levels compared to subjects undergoing rehabilitation at the de-addiction center. The result showed that the de-addiction center offers remarkable success in lowering down the 6-MAM levels among the addicts undergoing a rehabilitation program.

\section{Statistical analysis}

Descriptive statistics were used to explain the characteristics of the heroin addicts belonging to two groups, i.e., random heroin addicts and the heroin addict subjects from the de-addiction center. The Kolmogorov-Smirnov test and Shapiro-Wilk test were applied to analyze the normality of the data. Furthermore, Levene's test was applied to test homogeneity of variance prior to applying the Mann-Whitney $U$ test to assure that there is no significant difference in variances of the two groups. Finally, since the data was not normally distributed, so the Mann-Whitney $U$ test was applied to demonstrate the difference in 6-MAM levels between the two groups (Fig. 4).

\section{Discussion}

The scope of hair analysis depends upon the detection of the drug and/or its metabolite, followed by its quantification in the hair matrix [22]. A hair does not have its own metabolism or excretion system for flushing out the

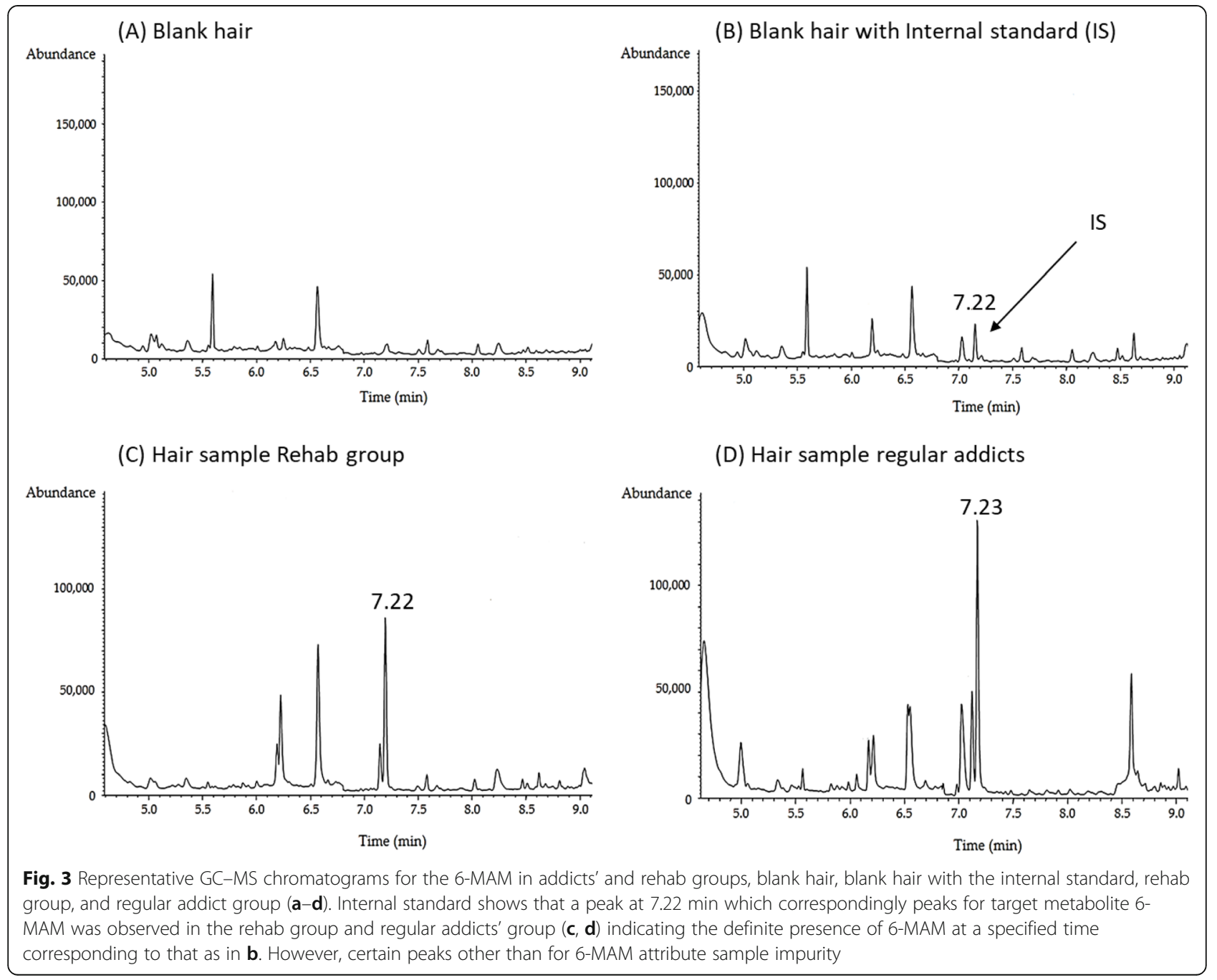




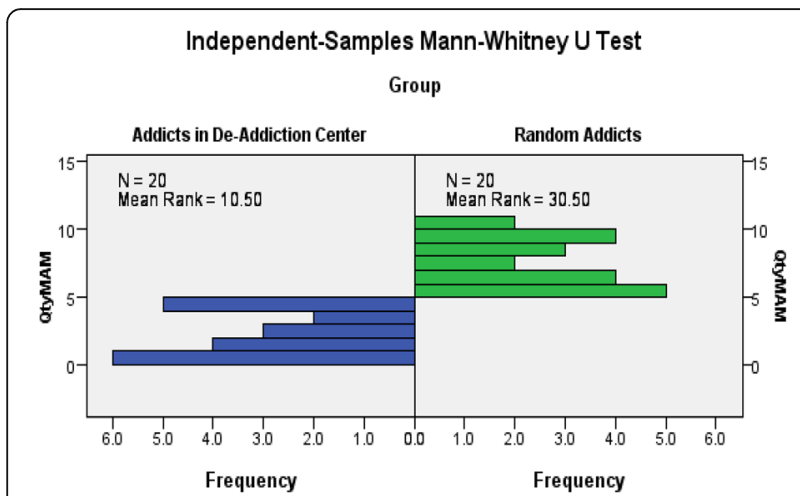

Fig. 4 Mann-Whitney $U$ statistics, frequency distribution for 6-MAM concentration in random heroin addicts' group and addicts going through rehabilitation at the de-addiction center group. There is a significant difference between mean rank for addicts undergoing rehabilitation compared to random regular addicts for 6-MAM levels in the hair sample

drugs that get incorporated into it [23]. Hair analysis has an important place in forensic toxicology. In majority of cases, by the time drug-facilitated crimes were reported to the police, the drugs in question were frequently eliminated from the more conventional route, such as blood or urine, also keeping in mind the fact that hair does not decay as compared to other biological samples [24]. In the current study, the quantity of 6-MAM in regular heroin addicts was found to be in a range of 5.46-10.7 $\mathrm{ng} / \mathrm{mg}$ (mean value, $7.80 \mathrm{ng} / \mathrm{mg}$ ) and that of subjects going through rehabilitation at the de-addiction center was in the range of $0.39-4.65 \mathrm{ng} / \mathrm{mg}$ (mean value, $2.34 \mathrm{ng} /$ $\mathrm{mg}$ ), which is consistent with the prior findings led by Klug et al. and Marigo et al. in accordance with their findings $[25,26]$. They had fulfilled the necessities for hair analysis by validating the RIA results by thin-layer chromatography (TLC) with fluorescence detection and using HPLC with fluorometric detection [27]. Goldberger et al. identified heroin and 6-acetylemorphine for the first time in 1991 using GC-MS for the detection of drug in the hair sample [28]. Kintz et al. in 1992 confirmed the existence of morphine in the hair sample ranging from 0.41 to $11.74 \mathrm{ng} / \mathrm{mg}$, which is also consistent with the results of the present study [8]. In the current study, we analyzed the level of 6-MAM in regular heroin addicts and in subjects undergoing rehabilitation at the de-addiction center. It is morphine and more recently 6-MAM, the chief metabolite of heroin, which are associated with significant consideration in the field of forensic science [29]. The results obtained confirmed the presence of noticeable levels of 6 -MAM in $100 \%$ of the samples, even 30 days after the abstinence of heroin. Therefore, on the basis of previous studies and results and findings of our study, it can therefore be concluded that in heroin addicts 6-MAM remains in hair samples even after 30 days of its abstinence.
Moreover, it requires further study to precisely determine the transit time of the noticeable metabolite of heroin in the hair sample. In the future, more studies will need to be carried out to ascertain the timeframe window for the drug and/or its metabolites' retention time in hair samples of definite heroin abusers.

\section{Conclusion}

It can be concluded that the method was successful in detecting the immediate metabolite of heroin, i.e., 6monoacetylmorphine (6-MAM), in the hair samples of heroin abusers. This study undoubtedly advocates that once 6-MAM gets combined with hair follicles, it will remain at that place for more than 30 days after the last intake. However, in the future, the advancement of scientific tools and sophistication in analytical techniques will further facilitate the investigation of abused drugs at even lower limits with greater accuracy. These data also propose that hair analysis for 6-monoacetylmorphine can be used to discriminate heroin users from other types of opiate exposure (e.g., poppy seed, licit morphine, and codeine).

\section{Abbreviations}

DAM: Diacetylmorphine; 6-MAM: 6-Monoacetylmorphine; CRM: Certified Reference Material; MTBE: Methyl tertiary butyl ether; DCM: Dichloromethane; TLC: Thin-layer chromatography; RIA: Radioimmune assay; HPLC: Highpressure liquid chromatography; GC-MS: Gas chromatography-mass spectrometry; IS: Internal standard; SIM: Selective ion monitoring; SD: Standard deviation; QC: Quality control; NPB: National Police Bureau; FDA: Food and Drug Administration; ORIC: Office of Research, Innovation and Commercialization

\section{Supplementary Information}

The online version contains supplementary material available at https://doi. org/10.1186/s43094-021-00245-z.

Additional file 1. Supplementary data.

\section{Acknowledgements}

We are really thankful to the Pakistan Council of Scientific \& Industrial Research Laboratories Complex (PCSIR) Pakistan for providing us the facilities to conduct research work. We are also thankful to laboratory staff for their invaluable support. We are highly thankful to the University laboratory staff who are always there to assist us even during the off hours.

\section{Authors' contributions}

'MAG' and 'FH' design project, sample collection, sample analysis, and writing the original manuscript; ' $Y H^{\prime}$ ' and ' $N A$ ' statistical analysis and technical support; and 'AA' interpreted the results, supervised the work, and provided technical guidance. Moreover, all authors have read and approved the final manuscript.

\section{Funding}

None

Availability of data and materials

Data and material are available upon request. 


\section{Declarations}

\section{Ethics approval and consent to participate}

The study approval was given by the Department of Chemistry and Life Sciences, Government College University (GCU), Lahore, with approval letter number, GCU/1-056/CLS. The participants were included after approval from the "Office of Research, Innovation and Commercialization" (ORIC) with reference number 2017-0057. All the participants were informed about the study protocol and then included after thoroughly briefing about the research purpose as directed from the ORIC in the ethical guideline. The participants agree to co-operate for the said purpose by giving their written and verbal consent, which was in accordance with ORIC guidelines.

\section{Consent for publication}

Written consent was taken from all participants.

\section{Competing interests}

The authors declare that they have no competing interests.

\section{Author details}

'Department of Pharmacy, Faculty of Science, University of the Punjab, Lahore, Pakistan. ${ }^{2}$ Department of Chemistry, Faculty of Life Science, Government College University, Lahore, Pakistan. ${ }^{3}$ School of Management, Department of Management Science and Engineering Xi'an Jiaotong University, Xi'an, China.

Received: 16 November 2020 Accepted: 16 April 2021 Published online: 07 May 2021

\section{References}

1. Giovannelli M, Bedforth N, Aitkenhead A (2008) Survey of intrathecal opioid usage in the UK. Eur J Anaesthesiol. 25(2):118-122. https://doi.org/10.1017/ S0265021507001305

2. Chronister CW, Gund AL, Goldberger BA (2008) Rapid detection of opioids in vitreous humor by enzyme immunoassay. J. Anal. Toxicol. 32(8):601-604 https://doi.org/10.1093/jat/32.8.601

3. Khallouki F, Breuer A, Akdad M (2020) Cytotoxic activity of Moroccan Melissa officinalis leaf extracts and HPLC-ESI-MS analysis of its phytoconstituents. Futur J Pharm Sci 6(1):1-12

4. Khajuria H, Nayak BP (2016) Detection and accumulation of morphine in hair using GC-MS. Egypt J. Forensic Sci. 6(4):337-341. https://doi.org/10.101 6/j.ejfs.2015.12.002

5. Druid H, Strandberg JJ, Alkass K, Nyström I, Kugelberg FC, Kronstrand R (2007) Evaluation of the role of abstinence in heroin overdose deaths using segmental hair analysis. Forensic Sci. Int. 168(2-3):223-226. https://doi.org/1 0.1016/j.forsciint.2006.02.047

6. Romano G, Barbera N, Spadaro G, Valenti V (2003) Determination of drugs of abuse in hair: evaluation of external heroin contamination and risk of false positives. Forensic Sci. Int. 131(2-3):98-102. https://doi.org/10.1016/S03 79-0738(02)00413-9

7. Baumgartner WA, Hill V, Blahd WH (1989) Hair analysis for drugs of abuse. J. Forensic Sci 34(6):1433-1453

8. Kintz P, Ludes B, Mangin P (1992) Detection of drugs in human hair using Abbott ADx, with confirmation by gas chromatography/mass spectrometry (GC/MS). J. Forensic Sci. 37(1):328-331

9. Milman G, Barnes AJ, Lowe RH, Huestis MA (2010) Simultaneous quantification of cannabinoids and metabolites in oral fluid by twodimensional gas chromatography mass spectrometry. J. Chromatogr. A. 1217(9):1513-1521. https://doi.org/10.1016/j.chroma.2009.12.053

10. Han E, Choi H, Lee S, Chung H, Song JM (2011) A comparative study on the concentrations of 11-nor- $\Delta$ 9-tetrahydrocannabinol-9-carboxylic acid (THCCOOH) in head and pubic hair. Forensic Sci Int 212(1-3):238-241. https://doi.org/10.1016/j.forsciint.2011.06.026

11. Han E, Chung H, Song JM (2012) Segmental hair analysis for 11-Nor- $\Delta 9$ tetrahydrocannabinol-9-carboxylic acid and the patterns of cannabis use. $J$ Anal Toxicol 36(3):195-200. https://doi.org/10.1093/jat/bks010

12. Auwärter V, Wohlfarth A, Traber J, Thieme D, Weinmann W (2010) Hair analysis for $\Delta$ 9-tetrahydrocannabinolic acid $A$-new insights into the mechanism of drug incorporation of cannabinoids into hair. Forensic Sci Int 196(1-3):10-13, Hair analysis for $\Delta$ 9-tetrahydrocannabinolic acid A-New insights into the mechanism of drug incorporation of cannabinoids into hair. https://doi.org/10.1016/j.forsciint.2009.12.023

13. Kronstrand R, Grundin R, Jonsson J (1998) Incidence of opiates, amphetamines, and cocaine in hair and blood in fatal cases of heroin overdose. Forensic Sci. Int. 92(1):29-38. https://doi.org/10.1016/S0379-073 8(98)00003-6

14. Minoli M, Angeli I, Ravelli A, Gigli F, Lodi F (2012) Detection and quantification of 11-nor- $\Delta$ 9-tetrahydrocannabinol-9-carboxylic acid in hair by $\mathrm{GC} / \mathrm{MS} / \mathrm{MS}$ in negative chemical ionization mode $(\mathrm{NCl})$ with a simple and rapid liquid/liquid extraction. Forensic Sci. Int. 218(1-3):49-52. https://doi.org/10.1016/j.forsciint.2011.10.014

15. Lee D, Milman G, Barnes AJ, Goodwin RS, Hirvonen J, Huestis MA (2011) Oral fluid cannabinoids in chronic, daily cannabis smokers during sustained, monitored abstinence. Clin. Chem. 57(8):1127-1136. https://doi.org/10.1373/ clinchem.2011.164822

16. Rathod RH, Chaudhari SR, Patil AS, Shirkhedkar AA (2019) Ultra-high performance liquid chromatography-MS/MS (UHPLC-MS/MS) in practice: analysis of drugs and pharmaceutical formulations. Futur J Pharm Sci 5(1):1-26

17. Bhattacharya S (2021) Preparation and characterizations of glyceryl oleate ufasomes of terbinafine hydrochloride: a novel approach to trigger Candida albicans fungal infection. Futur J Pharm Sci 7(1):1-11

18. Zambakjian C, Sakur AA (2020) A new gas chromatographic method development and validation for the simultaneous determination of ibuprofen and caffeine in bulk and pharmaceutical dosage form. Futur J Pharm Sci 6(1):1-8

19. Orfanidis A, Mastrogianni O, Koukou A, Psarros G, Gika H, Theodoridis G, Raikos N (2017) A GC-MS method for the detection and quantitation of ten major drugs of abuse in human hair samples. J. Chromatogr. B Anal. Technol. Biomed. Life Sci. 1047:141-150. https://doi.org/10.1016/j.jchromb.2 016.11.011

20. Wille SMR, Coucke W, De Baere T, Peters FT (2018) Update of standard practices for new method validation in forensic toxicology. Curr Pharm Des 23(36):5442-5454

21. Baillif-Couniou V, Kintz P, Sastre C, Pok PRP, Cheze M, Pépin G, PelissierAlicot AL (2015) Hair testing in postmortem diagnosis of substance abuse: an unusual case of slow-release oral morphine abuse in an adolescent. J Forensic Leg Med 36:172-176. https://doi.org/10.1016/j.jflm.2015.08.014

22. Gray B, Viljanto M, Menzies E, Vanhaecke $L$ (2018) Detection of prohibited substances in equine hair by ultra-high performance liquid chromatography-triple quadrupole mass spectrometry-application to doping control samples. Drug Test. Anal. 10(7):1050-1060. https://doi.org/1 $0.1002 / d t a .2367$

23. Pego A, Roveri F, Kuninari R, Leyton V, Miziara I, Yonamine M (2017) Determination of cocaine and its derivatives in hair samples by liquid phase microextraction (LPME) and gas chromatography-mass spectrometry (GCMS). Forensic Sci Int 274:83-90. https://doi.org/10.1016/j.forsciint.2016.12.024

24. Ruisen $X$, Ping $H$, Hong $W$, Jinwei $L$ (2018) Study on the extraction rate of morphine before and after hair grinding. J Drug Design Med Chem 4(1):1-4 https://doi.org/10.11648/j.jddmc.20180401.11

25. Tassoni G, Mirtella D, Zampi M, Ferrante L, Cippitelli M, Cognigni E, Froldi R, Cingolani M (2014) Hair analysis in order to evaluate drug abuse in driver's license regranting procedures. Forensic Sci. Int. 244:16-19. https://doi.org/1 0.1016/j.forsciint.2014.07.025

26. Klug E (1980) Determination of morphine in human hair (author's transl). Zeitschrift fur Rechtsmedizin. J Leg Med 84(3):189-193

27. Marigo M, Tagliaro F, Poiesi C, Lafisca S, Neri C (1986) Determination of morphine in the hair of heroin addicts by high performance liquid chromatography with fluorimetric detection. J. Anal. Toxicol. 10(4):158-161. https://doi.org/10.1093/jat/10.4.158

28. Goldberger BA, Caplan YH, Maguire T, Cone EJ (1991) Testing human hair for drugs of abuse. III. Identification of heroin and 6-acetylmorphine as indicators of heroin use. J. Anal. Toxicol. 15(5):226-231

29. Ramya KR, Thangam R, Madhan B (2020) Comparative analysis of the chemical treatments used in keratin extraction from red sheep's hair and the cell viability evaluations of this keratin for tissue engineering applications. Process Biochem. 90:223-232. https://doi.org/10.1016/j. procbio.2019.11.015

\section{Publisher's Note}

Springer Nature remains neutral with regard to jurisdictional claims in published maps and institutional affiliations. 